\title{
OS ATAQUES ÀS CORTES CONSTITUCIONAIS E O ATIVISMO JUDICIAL DESMEDIDO COMO MANIFESTAÇÕES DE UM ESTADO PÓS-DEMOCRÁTICO
}

${ }^{1}$ CAMPIS, K. F, ${ }^{2 B I T E N C O U R T, ~ M . ~ C . ~}$

PALAVRAS-CHAVE: Estado pós-democrático. Ativismo judicial. Direito Constitucional. América do Sul. Cortes Constitucionais.

\section{RESUMO}

O tema do presente trabalho é o alargamento da interpretação do direito por parte do Poder Judiciário, que tem se valido da opinião pública para subverter garantias constitucionais, sendo que o próprio Tribunal Constitucional quando se posiciona no sentido de proteger tais garantias, é alvo de ataques do público e de outras instituições. Como objetivos, destacam-se a análise da relação entre constitucionalismo, separação dos poderes e democracia; do ativismo judicial desmedido como sintoma do autoritarismo presente em instituições como o Poder Judiciário e o questionamento sobre a possibilidade de a democracia no Brasil estar em declínio. A metodologia utilizada é a revisão bibliográfica, baseada em autores que têm contribuído com o tema das teorias da democracia, e da atual situação brasileira. Também se vale de notícias de jornal, uma vez que a situação de diferentes regimes (aparentemente) democráticos têm ocupado as manchetes dos jornais e portais de notícias. Uma das conclusões do trabalho é de que a democracia brasileira se encontra em crise, e que apesar da normalidade aparente em que se encontram as instituições, é possível considerar que o país está imerso em um estado de exceção, sobretudo judicial.

\section{THE ATTACKS TO THE CONSTITUCIONAL COURTS AND THE UNMEASURED JUDICIAL ACTIVISM AS MANIFESTATIONS OF AN POST DEMOCRATIC STATE}

\author{
KEYWORDS: Post-democratic State. Judicial activism. Constitucional Rights. South America. Constitucional
}

Courts.

\begin{abstract}
The subject of the present work is the extension of the interpretation of the Law by the Judiciary, which has used public opinion to subvert constitutional guarantees, and when the Constitutional Court itself is positioned to protect such guarantees, it has been the target of attacks from the public and other institutions. As objectives, the analysis of the relation between constitutionalism and democracy stands out; of unbridled judicial activism as a symptom of authoritarianism present in institutions such as the Judiciary and the questioning of the possibility of democracy in Brazil being in decline. The methodology used is the bibliographic review, based on authors who have contributed to the theme of democracy theories, and the current Brazilian situation. It also draws on newspaper news, as the situation of different (seemingly) democratic regimes has occupied the headlines of newspapers and news portals. One of the conclusions of the study is that Brazilian democracy is in crisis, and that despite the apparent normality of the institutions, it is possible to consider that the country is immersed in a state of exception, especially judicial.
\end{abstract}

${ }^{1}$ Acadêmico do curso de Direito do $10^{\circ}$ semestre, Presidente do Diretório acadêmico Arthur Germano Fett e Pesquisador Fapergs. E-mail: fkcampis@hotmail.com

2 Doutora em Direito, docente no Programa de Pós - Graduação em Direito - Universidade de Santa Cruz do Sul. E-mail: carolinemb@unisc.br 


\section{INTRODUÇÃO}

0 presente trabalho foi elaborado a partir do projeto de pesquisa realizado no ano de 2019 , teve como objetivo específicos compreender dois movimentos crescentes no mundo e seus possíveis e eminentes efeitos sobre o Brasil. 0 primeiro deles é o ataque às cortes constitucionais e à legalidade. 0 discurso contrário ao império da lei e às instituições democráticas como um todo fica cada vez mais evidente em protestos, tanto nas ruas quanto nas redes. Situações que aconteceram em outros países, como na Polônia e na Venezuela, revelam que o enfraquecimento de tais órgãos são os primeiros passos que uma nação toma em direção ao autoritarismo.

0 ativismo judicial negativo desmedido, segundo objeto de análise especifica, tem surgido como um fenômeno moderno no Brasil, cujo Estado Democrático de Direito adota uma constituição prolixa ${ }^{1}$ e o sistema romano-germânico de direito, no qual todos estão diretamente vinculados à constituição e à legalidade. No entanto, diversas decisões arbitrárias de juízes simplesmente a atropelam. Essas decisões de juízes solipsistas², além de desrespeitarem diretamente a normativa, vêm colaborando diretamente para o fenômeno descrito no parágrafo anterior, na medida em que juízes, desembargadores, promotores e procuradores federais simplesmente desobedecem a normativa legal. Muitos desses, quando sofrem reveses nas cortes superiores em razão do estrito cumprimento da legalidade, convocam a mídia e a população para atacarem não apenas as decisões do judiciário, mas a legalidade como um todo. 0 resultado de anos de ativismo judicial e descumprimento das leis materiais e processuais estourou no enorme escândalo trazido à luz no dia 09/06/2019 pelo The Intercept Brasil.

Este trabalho se justifica pelo fato de se compreender que a democracia é o único sistema onde existe qualquer forma de controle social e possibilidade de exercício para a cidadania. Na medida que a solução dada por parcelas sociais para os problemas da justiça são os ataques às instituições democráticas, começam os sintomas de um estado pós-democrático. Quanto ao método de abordagem deste estudo, será utilizado o método hermenêutico. Sendo assim, por meio da fenomenologia hermenêutica heideggeriana, a linguagem e os fatos não são analisados em um sistema fechado de referências, mas no plano da historicidade. Os métodos de procedimento se constituem no histórico e no monográfico, ao passo que as técnicas de pesquisa empregadas serão a bibliográfica e a documental.

\section{CONSTITUCIONALISMO TUPINIQUIM: ATIVISMO JUDICIAL NEGATIVO VERSUS FORÇA NORMATIVA DA CONSTITUIÇÃO - UM SINTOMA DO AUTORITARISMO}

Recentemente, surgiram diversas manifestações - principalmente nas redes sociais - que pediam o impeachment de ministros do STF e, em muitos casos, a derrubada da Corte Constitucional. A maioria dessas manifestações possui, em seu cerne, a ignorância fomentada por fake news e uma total incompreensão do papel de uma Corte Constitucional.

\footnotetext{
1 Prolixa ou extensa no sentido de ser detalhista e explicar diversos tópicos.

2 Alguns juristas e pensadores contemporâneos, como Lenio Streck, vêm usando o termo solipsista para descrever juízes e ministros que simplesmente atropelam a lei e a constituição e fazem o que podemos chamar de uma interpretação própria desvinculada da legalidade e da realidade dos fatos.
} 
As Cortes Constitucionais, ao redor do mundo, devem desempenhar um papel contramajoritário de interpretar e defender o que está positivado na constituição, que é um remédio contra maiorias. Nos Estados Unidos, na França, na Alemanha e em quase todas as democracias modernas, pelo menos é isso que acontece. Então, quando políticos e pessoas públicas falam que o STF deveria ouvir as vozes das ruas, eles não poderiam estar mais equivocados; pois, dos três poderes, o único que não deve ouvir as ruas é o judiciário.

Em um estudo detalhado, Levitsky e Zibblat (2018) mostram que em países com democracias desestabilizadas, as Cortes Constitucionais foram as primeiras instituições a serem atacadas: a Hungria ${ }^{3}$, por exemplo, em meados de 2018, criou um sistema judicial paralelo controlado pelo presidente, que tem o poder de decidir questões sensíveis, como crimes de corrupção, leis eleitorais, o direito à manifestação, etc. Atualmente, o presidente da Hungria está livre para fechar universidades, perseguir opositores, jornalistas e todos que o desafiarem ${ }^{4}$.

Na Polônia ${ }^{5}$, uma reforma tentou forçar mais de um terço dos juízes da Suprema Corte a se aposentarem, e ela só foi barrada depois de fortes manifestações e ameaças da União Europeia. Mas esses ataques à estabilidade dos guardiões da Constituição não acontecem somente em governos de extrema direita. $\mathrm{Na}$ Venezuela6, em 2003, Hugo Chávez aumentou o número de ministros da Suprema Corte de 20 para 32.0 enfraquecimento e o desvio de finalidade das Cortes Constitucionais é um sintoma para o fim de uma democracia saudável e, no Brasil, esse sintoma está começando a se manifestar.

É comum ver nos tabloides e nas redes sociais manifestações furiosas de pessoas contrárias a decisões do Supremo Tribunal Federal - STF e demais órgãos jurisdicionais, simplesmente por cumprirem suas funções e aplicarem a lei como ela é. Essa situação fica ainda mais sintomática quando estudantes de direito e advogados aplaudem decisões ativistas de órgãos do judiciário que contrariam claramente princípios constitucionais. Ademais, juízes que simplesmente julgam como acreditam ser mais conveniente, sem prezar pela lei e/ou por princípios constitucionais são tidos como heróis, e juízes que cumprem a lei são publicamente taxados de criminosos. Membros do Ministério público vêm insistindo em teses absurdas (que muitas vezes são acatadas), como a distribuição de processos por crimes eleitorais e conexos para a justiça comum, o que configuraria uma nulidade absoluta, visto que fere matéria de ordem constitucional. Por isso o fenômeno do ativismo judicial também merece destaque em meio a essa crise, para tanto cabe primeiramente identificar suas duas grandes espécies, o primeiro ativismo tem como característica o fato de visar efetivar direitos e garantias individuais positivados na constituição, por isso recebe a alcunha de ativismo positivo, já o segundo ativismo tem raízes mais profundas, ele é o resultado do que Lênio Streck (2017, p. 269) conceitua como senso comum teórico e solipsismo, quando juízes e pessoas com poder de decisão optam por deixar de lado o cumprimento da lei e legalidade, esse ativismo está diretamente relacionado com o derrocada de várias democracias, na medida de que as raízes das democracias liberais, como a separação de poderes, o império da lei, a liberdade de imprensa e até a expressão artística 7são corroídas em nome de interesses espúrios de membros do judiciário, mais do que

\footnotetext{
3 Ver matéria jornalística publicada no Jornal O Globo: “Hungria cria sistema judicial paralelo e consolida controle de Orbán sobre o Judiciário”. 2019.

4 Ver matéria do estadão que detalha alguns ataques a universidade, jornalistas e opositores. Disponível em: https://internacional.estadao.com.br/noticias/geral,sob-escudo-da-economia-premie-orban-mina-democraciana-hungria,70002834169

5 Ver matéria jornalística em Deutsche Welle. UE abre procedimento inédito contra Polônia. 2019.

6 Ver matéria jornalística em Folha de São Paulo. Chávez aumenta número de juízes na Corte Suprema venezuelana. 2003.

7 Ver matéria jornalística em Estadão.
} 
uma discussão acerca da separação dos poderes, o ativismo judicial nos propõe uma discussão acerca do que atualmente representam os limites entre Direito e Política. John Locke (Russel, 2019) o mais notório liberal, conceituava que a razão de existência do estado está diretamente ligada ao fato de as pessoas serem péssimos juízes em causa própria e que se não existisse um terceiro ( 0 estado) para dirimir os conflitos sociais esses resultariam em enormes injustiças e brutalidade, e é exatamente isso que conceitua um juiz, promotor ou procurador, o fato de colocar seus interesses individuais subjetivos acima do estado em sua atuação em nome do estado, e é exatamente isso que todos os juristas, sejam eles positivistas, interpretativistas, Waldrianos, desde que comprometidos com a democracia buscam combater desde Kelsen.

Quando o STF decide contra os ativismos e as decisões de juízes solipsistas, existem ameaças de morte e sérios riscos de ministros sofrerem impeachment ${ }^{8}$, seja por forte pressão popular, seja por contrariar o interesse de certos grupos políticos. O maior exemplo disso é a flagrantemente ilegal prisão em segunda instância, a qual, quando contestada pelo ministro Marco Aurélio Mello, gerou fortes alvoroços na mídia, no núcleo do exército e em camadas populares. As manifestações que atualmente estão sendo convocadas para 15 de março não são nada além de um ataque generalizado às instituições democráticas que conta com o apoio de diversos setores reacionários e favoráveis à um retorno dos tempos do Al-5. Vale destacar que a incompreensão por grande parte da população brasileira de que o Poder Judiciário existe como órgão que julga conflitos morais em relação à lei e não à moral é um dos principais vetores que ensejaram na ruptura (Castells, 2018) entre a identidade da população e das instituições democráticas, pois a dificuldade que os brasileiros (inclusive muitos políticos ), tem para entender que o poder judiciário não é um órgão imperativo que se sobressai aos outros poderes e à constituição é um fenômeno preocupante. É preciso que se compreenda o papel do Supremo Tribunal Federal de resolver conflitos com base na Constituição, de forma que as críticas dirigidas sejam em razão de não cumprir a constituição como ele deveria, como nos casos de censura por parte dos ministros Alexandre de Moraes, Dias Toffoli e Luiz Fux ${ }^{9}$, e não em razão de se fazer valer o que Konrad Hesse $(1959$, p. 8) apontava como força normativa da Constituição.

Em síntese, o que deve prevalecer em uma democracia é o que Rousseau chamou de vontade geral, a expressão política da vontade do soberano, o povo, o qual deve obedecer a si mesmo e às decisões políticas que foram democraticamente tomadas em seu nome. Correspondendo ao enunciado da vontade geral e, consequentemente, pertencendo ao interesse público, as leis devem estar acima dos interesses particulares, e a constituição deve estar acima de tudo. Quando o contrário acontece, os abusos resultantes culminam na sociedade corrompida da qual Rousseau desejava se afastar. E se não existir um órgão capaz de fazer valer a força normativa da Constituição (HESSE, 1959), a democracia começa a se enfraquecer e a se desviar de suas finalidades.

É preciso entender que nem sempre a maioria está certa e, para que o estado de direito não chegue a um fim, são necessários limites estabelecidos na lei e em uma carta magna, as quais devem ser prezadas e respeitadas, assim como a corte constitucional responsável por sua defesa. Na Alemanha nazista, a ascensão de Hitler ao poder contou com imenso apoio popular, e muitos, inclusive opositores, confiavam que o Führer não poderia fazer tudo o que afirmava, pois com a Constituição de Weimar ele estaria impedido. Uma vez fragilizada

\footnotetext{
8 Ver matéria jornalística em Estadão. Marco Aurélio suspende prisão em $2^{\mathrm{a}}$ instância e abre caminho para Lula. 2019.

${ }^{9}$ Ver matéria jornalística em 0 Globo: Alexandre de Moraes revoga decisão que censurou reportagens de 'Crusoé' e '0 Antagonista'. 2019. 
a força normativa da Constituição alemã, o caos tomou o lugar da democracia e o holocausto aconteceu. Lenio Streck (2019), em uma recente coluna no Conjur, nos lembra de que

\begin{abstract}
...Michael Stolleis, com apoio em Bernd Rüthers, bem denunciava um período no qual a interpretação no Direito era unrestrained, ou seja, não-constrangida. Alertava igualmente para a moralização que instrumentalizava o Direito para determinados fins políticos. E qual era esse período? Um período que ficou conhecido como III Reich. Alemanha Nazista (STRECK, 2019, online).
\end{abstract}

Todos os elementos até aqui trazidos demonstram que existe um risco iminente de caos democrático, na medida em que, no atual momento histórico, a abundância de fake news, o desprezo pela verdade, o ódio à política e às instituições democráticas e a busca por uma ordem social capitaneada por um messias constituem os novos ingredientes para uma morte lenta e quase imperceptível do que ainda nos resta de democracia.

\title{
3 ESTARIA NOSSA DEMOCRACIA MORRENDO?
}

Os professores de Harvard, Steven Levitsky e Daniel Ziblatt,, estudiosos das teorias da democracia, afirmam em seu livro Como as democracias morrem que, atualmente, não são mais necessários tanques e exércitos armados para destituir governos democraticamente eleitos e subverter a ordem democrática. Segundo os autores, "desde o final da Guerra Fria, a maior parte dos colapsos democráticos não foi causada por generais e soldados, mas pelos próprios governos eleitos" (LEVITSKY; ZIBLATT, 2018, p. 16).

\footnotetext{
Muitos esforços do governo para subverter a democracia são "legais", no sentido de que são aprovados pelo Legislativo ou aceitos pelos tribunais. Eles podem até mesmo ser retratados como esforços para a perfeiçoar a democracia - tornar o Judiciário mais eficiente, combater a corrupção ou limpar o processo eleitoral. Os jornais continuam a ser publicados, mas são comprados ou intimidados e levados a se autocensurar. Os cidadãos continuam a criticar o governo, mas muitas vezes se veem envolvidos em problemas com impostos ou outras questões legais (LEVITSKY; ZIBLATT, 2018, p. 17).
}

O fato de existir certa "normalidade" no cotidiano cria, segundo os autores, confusão e perplexidade, pois as pessoas acreditam estar vivendo sob uma democracia. Dispositivos de alarme, que seriam naturalmente disparados na sociedade caso houvesse um evento que rompesse com a normalidade democrática (como a suspensão da Constituição, por exemplo), não se manifestam. A consequência é que "a erosão da democracia é, para muitos, quase imperceptível." (LEVITSKY; ZIBLATT, 2018, p. 17).

Como dito na primeira parte deste texto e referendado por Boaventura de Sousa Santos, o contrato social "é a expressão de uma tensão dialéctica (sic) entre regulação social e emancipação social que se reproduz pela polarização constante entre vontade individual e vontade geral, colectiva (sic), entre o interesse particular e o bem comum", preconizado por Rousseau (SANTOS, 2008, p. 317).

Tal definição vai ao encontro de Bobbio (2000), que apresenta uma concepção procedimental da democracia: para o autor, a democracia é um procedimento para a formação de decisões coletivas. Por regime democrático, entende-se um conjunto de regras de procedimento que estabelecem quem está autorizado a tomar as decisões vinculatórias para todos os membros do grupo e com quais procedimentos isso deve se dar. Por outro lado, o autor apresenta uma concepção individualista da sociedade, porque mesmo que o homem seja um ser 
social que não pode viver isolado, em suas relações com a sociedade, o indivíduo se reúne a outros, semelhantes a ele, dando origem a uma sociedade de indivíduos livres.

Sendo assim,

\begin{abstract}
...o discurso sobre as regras do jogo é extremamente importante, e não pode ser eliminado se não se deseja cair diante de um problema mal posto e, nesta medida, insolúvel. E isto ao menos por duas razões. Antes de mais nada, porque o que distingue um sistema democrático dos sistemas não democráticos é um conjunto de regras do jogo. Mais precisamente, o que distingue um sistema democrático não é apenas o fato de possuir as suas regras do jogo (todo sistema as tem, mais ou menos claras, mais ou menos complexas), mas sobretudo o fato de que estas regras, amadurecidas ao longo de séculos de provas e contraprovas, são muito mais elaboradas que as regras de outros sistemas $e$ encontram-se hoje, quase por toda parte, constitucionalizadas [...] quem não se deu conta de que por sistema democrático entende-se hoje preliminarmente um conjunto de regras procedimentais, das quais a regra da maioria é a principal mas não a única, não compreendeu nada e continua a não compreender nada a respeito da democracia (BOBBIO, 2000, p. 77).
\end{abstract}

O jogo democrático é constituído de regras claras para todos os atores envolvidos, mas também de regras informais, o que garante o equilíbrio democrático baseado não somente nos textos constitucionais, mas também naquilo que poderíamos chamar de um acordo tácito. Para Levitsky e Ziblatt (2018), essas regras consistem na tolerância mútua, ou seja, o reconhecimento de que os adversários ou rivais, desde que dentro das regras institucionais, têm direitos iguais de jogar o jogo democrático (direito de existir, de competir pelo poder e de governar). A outra regra é a reserva institucional, que significa ser necessário evitar ações que, embora estejam dentro da lei, violem seu espírito.

A violação dessas regras conduz ao que o professor Rafael Valim (2017) chama de "estado de exceção"10, sendo um dos exemplos o combate à corrupção promovido por autoridades judiciárias brasileiras nos últimos anos. Sob esse pretexto, são exaradas decisões judiciais de caráter excepcional, o que tem sido chamado de "estado de exceção judicial” (p. 16).

Nesse sentido, estaríamos, hoje, diante do que Boaventura de Sousa Santos (2008) chama de uma crise do contrato social, em que valores característicos da modernidade ocidental (liberdade, igualdade, justiça e solidariedade) estão passando por uma sobrecarga simbólica crescente. Trata-se de um processo que privilegia “a predominância estrutural dos processos de exclusão sobre os processos de inclusão" (SANTOS, 2008, p. 327). Essa crise se alicerça em um conjunto de consensos nos campos político, econômico e social, tendo como uma de suas dimensões o "consenso do primado do direito e dos tribunais", que atribui um novo papel aos tribunais, sendo um de seus principais vieses a judicialização da política (SANTOS, 2008).

Para Valim (2017), é justamente o estado de exceção judicial o que caracteriza o fracasso do atual modelo de democracia, uma vez que abala um dos pilares do Estado Democrático de Direito, que é a soberania popular:

Em outras palavras, a exceção, ao negar a lei, principal produto da soberania popular, toma de assalto a democracia. A pretensão de um governo impessoal das leis cede lugar ao governo pessoal dos homens. 0 povo é destronado em favor do soberano, o que explica a

\footnotetext{
10 Para aprofundamento sobre o termo "estado de exceção", ver capítulo 1, "Estado de exceção: aproximação teórica e localização sistemática”, da obra Estado de Exceção: a forma jurídica do neoliberalismo, de Rafael Valim. Nele, o autor explora algumas definições sobre o tema a partir de diferentes autores.
} 
afirmação de Giorgio Agambem de que a exceção é o absolutismo da contemporaneidade. (VALIM, 2017, p. 27, grifos no original).

0 autor afirma que o estado de exceção acaba por potencializar o processo de despolitização da sociedade, o que não quer dizer que assuntos que pareciam consagrados no Direito Constitucional brasileiro, tidos como conquistas civilizatórias, estejam a salvo da discussão pública, sob forma de questionamentos sobre sua validade (VALIM, 2017).

No Brasil, há alguns anos, mais precisamente desde o início da operação Lava Jato em 2014, essa prática do Estado policialesco, onde os fins justificam os meios para o combate à corrupção, o estado de exceção judicial tem se imposto sobre as garantias fundamentais dos acusados. As denúncias do site The Intercept Brasil, de que Poder Judiciário e Ministério Público Federal estariam agindo em parceria para atingir determinado grupo político ou determinadas figuras políticas em detrimento de outras - com denúncias tão ou mais graves -, parece refletir esse estado de coisas.

O que temos observado no país é um crescente processo de ódio à política, fomentado por essas ações de suposto combate à corrupção, com atuação fundamental dos meios de comunicação, os quais fizerem com que um dito outsider político chegasse à Presidência da República. Diga-se de passagem, esse outsider é uma figura política não disposta a respeitar as regras democráticas, tendo em vista o conteúdo de suas ações e falas amplamente divulgadas ${ }^{11}$.

Mas Valim (2017, p. 41) entende que "o principal e mais perigoso agente da exceção no Brasil é o Poder Judiciário". 0 autor retoma os procedimentos da Operação Lava Jato, a qual, desde seu início, abusou de prisões cautelares de empresários e agentes públicos ao lado da grande espetacularização por parte da mídia e dos "vazamentos seletivos" de informações para grandes veículos de comunicação. Assim, foram criadas as condições sociais e políticas para o impeachment da presidenta democraticamente eleita. Cabe lembrar, ainda, que pouco antes da instauração do processo de destituição, a presidenta da República teve suas conversas telefônicas interceptadas, selecionadas e vazadas ao público por um juiz de primeira instância (hoje Ministro da Justiça), o qual alegava interesse público.

0 magistrado não só não foi punido pelo disposto na Lei $9.296 / 96$, que trata da interceptação de comunicações telefônicas, como teve seus procedimentos excepcionais referendados pelo Tribunal Regional da

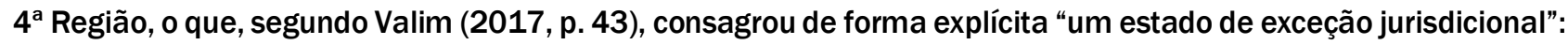

Os princípios do juiz natural, da imparcialidade e da presunção da inocência vêm sendo solenemente desconsiderados, sob os olhares cúmplices da mídia e a atenção de uma turba ignara que, a cada nova arbitrariedade, destila seu ódio nas ruas e nas redes sociais (VALIM, 2017, p. 44).

Como se não bastasse, o Supremo Tribunal Federal, fazendo coro ao estado de exceção jurisdicional, em dissonância com o texto constitucional, em seu artigo $5^{\circ}$, inciso LVII, cujo texto dispõe que ninguém será considerado culpado até o trânsito em julgado da sentença penal condenatória, abriu a possibilidade de prisão

\footnotetext{
11 Ver matéria jornalística de 0 Globo: Bolsonaro diz: "Não aceito resultado das eleições diferente da minha eleição", publicado em setembro de 2018. Revista Exame: "Vamos fuzilar a petralhada", diz Bolsonaro em campanha no Acre, publicado em setembro de 2018 . Revista Carta Capital: Bolsonaro em 25 frases polêmicas, publicado em 29 out, 2018.
} 
em segunda instância, ou seja, antes da confirmação da sentença condenatória. Juízes país afora têm emitido sentenças com base no "clamor das ruas". Mas quem decide quais vozes ouvir?

\section{CONCLUSÃO}

No presente trabalho procurei traçar um panorama sobre o atual cenário político e judicial brasileiro, baseado na hipótese de que existe uma crise institucional em curso que tem colocado o sistema democrático em crise $^{12}$. Para tanto, em um primeiro momento, foi analisada a relação entre democracia e constitucionalismo, concluindo que o contrato social, cujo soberano é o povo, está em risco. Em um segundo momento, buscou-se analisar os sintomas do autoritarismo presentes no embate entre ativismo judicial e força normativa da constituição, que tem sido alvo de debates entre defensores de maior autonomia - inclusive para intepretação legal - e aqueles que defendem respeito ao texto constitucional. Dessa forma, percebeu-se que o debate público, na era da pós-verdade, está contaminado de processos e procedimentos no mínimo questionáveis. Finalmente, na terceira parte do artigo, questionou-se acerca da morte da democracia no Brasil, desta vez não por meio de armas, tanques e soldados armados ou a suspensão da Constituição, mas por meio de procedimentos aparentemente democráticos. Na medida em que ainda temos eleições livres e instituições em funcionamento, não haveria que se falar em anormalidade democrática. Mas o fato é que, conforme apontado, o Brasil se encontra diante de um "estado de exceção", capitaneado, em grande medida, pelo Poder Judiciário com apoio dos grandes meios de comunicação, cujos métodos de alguns de seus integrantes seguem a clássica máxima de "os fins justificam os meios" quando se trata de combater a corrupção no país.

Dessa forma, está em curso o que o professor Rafael Valim chama de processo desconstituinte, em que, sob a conivência do Estado, especialmente do Poder Judiciário - mas hoje em dia também do Poder Executivo central - ataca-se todo catálogo de direitos fundamentais.

Diante de um processo de frequentes ataques às instituições democráticas, em especial à suprema corte e à teoria do Direito, capitaneado por setores reacionários, membros do judiciário adeptos destas ideologias deixam de lado as amarras da legalidade em nome de um projeto de poder, abrindo mão de qualquer argumentação jurídica, para usar de um ativismo judicial onde não importam os meios apenas o fim.

\section{AGRADECIMENTOS}

Gostaríamos de agradecer primeiramente a FAPERGS, Fundação de amparo à pesquisa do Rio Grande do Sul, órgão que fomentou essa pesquisa através da bolsa de iniciação científica, em segundo lugar à UNISC e ao PPGD-UNISC, que proporcionaram um ambiente rico em discussões acadêmicas sem as quais esses projeto seria muito menos rico.

\footnotetext{
12 Para Rubens Casara, "crise democrática" é uma forma dócil de tratar os acontecimentos em curso, quando valores democráticos são substituídos pelas exigências do mercado. Para o jurista, estamos diante de um Estado pós-democrático, fenômeno global que não teve dificuldades de se instalar no Brasil devido à tradição autoritária do país, caracterizada pelo uso da força, pelo medo da liberdade e pelos pactos elitistas herdados da escravidão. Para ele, isso fez com que, no Brasil, a pós-democracia se instaurasse docilmente. (CULT, 2017). Por tudo visto até aqui, tendemos a concordar com este posicionamento.
} 


\section{REFERÊNCIAS}

BOBBIO, Norberto. 0 futuro da democracia. Tradução de Marco Aurélio Nogueira. $7^{\mathrm{a}}$ ed. rev. e ampl. Rio de Janeiro, Paz e Terra, 2000.

BRASIL. Lei 9.296/96. Regulamenta o inciso XII, parte final, do art. $5^{\circ}$ da Constituição Federal. Disponível em: <http://www.planalto.gov.br/ccivil_03/LEIS/L9296.htm>. Acesso em 09 jul. 2019.

CASTELLS, Manuel. Ruptura: a crise da Democracia Liberal. Tradução: Joana Angélica d'Avila. Rio de Janeiro: Zahar 2018

CARTA CAPITAL. Bolsonaro em 25 frases polêmicas. 2018. Disponível em: https://www.cartacapital.com.br/politica/bolsonaro-em-25-frases-polemicas/>. Acesso em 08 jul. 2019. DEUTSCHE WELLE. UE abre procedimento inédito contra Polônia. 2019. Disponível em: <https://www.dw.com/ptbr/ue-abre-procedimento-in\%C3\%A9dito-contra-pol\%C3\%B4nia/a-41879215>. Acesso em 01 de julho de 2019.

CULT. Pós-democracia instalou-se 'docilmente' no Brasil, diz jurista. Entrevista concedida por Rubens Casara à Paulo Henrique Pompermaier. 2017. Disponível em: <https://revistacult.uol.com.br/home/rubens-casaraestado-pos-democratico/>. Acesso em 10 jul. 2019.

ESTADÃO. Marco Aurélio suspende prisão em $2^{a}$ instância e abre caminho para Lula. 2019. Disponível em: <https://politica.estadao.com.br/blogs/fausto-macedo/marco-aurelio-mello-da-liminar-para-suspenderpossibilidade-de-prisao-apos-condenacao-em-2a-instancia/>. Acesso em 01 de julho de 2019.

EXAME. Vamos fuzilar a petralhada", diz Bolsonaro em campanha no Acre. 2018. Disponível em: <https://exame.abril.com.br/brasil/vamos-fuzilar-a-petralhada-diz-bolsonaro-em-campanha-no-acre/>. Acesso em: 08 jul. 2019.

FOLHA DE SÃO PAULO. Chávez aumenta número de juízes na Corte Suprema venezuelana. 2003. Disponível em: <https://www1.folha.uol.com.br/fsp/mundo/ft2510200317.htm>. Acesso em 01 de julho de 2019.

LEVITSKY, Steven; Ziblatt, Daniel. Como as democracias morrem. Tradução de Renato Aguiar. Rio de Janeiro: Zahar, 2018.

LEXICO OXFORD. Dictionary. Disponível em: <https://www.lexico.com/en>> acesso em 08 jul. 2019.

0 GLOBO. Alexandre de Moraes revoga decisão que censurou reportagens de 'Crusoé' e '0 Antagonista'. 2019. Disponível em: < https://g1.globo.com/politica/noticia/2019/04/18/alexandre-de-moraes-revoga-decisao-quecensurou-reportagens-de-crusoe-e-antagonista.ghtml>. Acesso em 01 de julho de 2019.

O GLOBO. Bolsonaro diz: “Não aceito resultado das eleições diferente da minha eleição”. 2018. Disponível em: <https://g1.globo.com/sp/sao-paulo/eleicoes/2018/noticia/2018/09/28/bolsonaro-diz-que-nao-aceitararesultado-diferente-do-que-seja-a-minha-eleicao.ghtml>. Acesso em 08 jul. 2019.

O GLOBO. Hungria cria sistema judicial paralelo e consolida controle de Orbán sobre o Judiciário. 2019. Disponível em: <https://oglobo.globo.com/mundo/hungria-cria-sistema-judicial-paralelo-consolida-controle-de-orban-sobrejudiciario-23302480>. Acesso em 01 de julho de 2019.

RUSSEL, Bertrand. História da Filosofia ocidental. Novo tempo, 2019

SANTOS, Boaventura de Sousa. A gramática do tempo: por uma nova cultura política. 2ed. São Paulo: Cortez, 2008.

STIGLITZ, Joseph. 0 preço da desigualdade. Lisboa: Bertrand Editora, 2014.

STRECK, Lenio. Hermenêutica: Livro carta n.1. São Leopoldo, 2017 
STRECK, Lenio. Dicionário de Hermenêutica: quarenta temas fundamentais da teoria do Direito â luz da crítica hermenêutica do Direito. Belo Horizonte (MG): Letramento, 2017

STRECK, Lenio. O STF sendo atacado e o MP fica arrumando o Van Gogh da parede. 2019.Disponível em: <https://www.conjur.com.br/2019-abr-25/senso-incomum-stf-sendo-atacado-mp-fica-arrumando-van-goghparede>. Acesso em 01 de julho de 2019.

THE INTERCEPT BRASIL. Como e porque o Intercept está publicando chats privados sobre a lava jato e Sérgio Moro. Disponível em: <https://theintercept.com/2019/06/09/editorial-chats-telegram-lava-jato-moro/>. Acesso em 09 jul. 2019.

VALIM, Rafael. Estado de exceção: a forma jurídica do neoliberalismo. São Paulo: Contracorrente, 2017. 